\title{
STATUS OF FOUR-JUNCTION CELL DEVELOPMENT AT FRAUNHOFER ISE
}

\author{
D. Lackner ${ }^{(1, *)}$, O. Höhn ${ }^{(1)}$, A.W. Walker ${ }^{(1)}$, M. Niemeyer $^{(1)}$, P. Beutel $^{(1)}$, G. Siefer ${ }^{(1)}$, M. Schachtner ${ }^{(1)}$ V. Klinger $^{(1)}$,

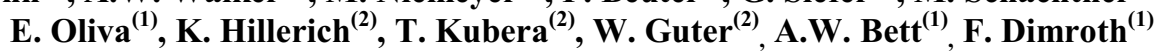 \\ (1) Fraunhofer Institute for Solar Energy Systems ISE, Heidenhofstrasse 2, 79211 Freiburg (Germany), \\ *Email: david.lackner@ise.fraunhofer.de \\ (2) AZUR SPACE Solar Power GmbH, Theresienstrasse. 2, 74072 Heilbronn, (Germany
}

\begin{abstract}
Four-junction solar cells are being developed for space applications as they promise higher efficiencies compared to the present $\mathrm{GaInP} / \mathrm{GaInAs} / \mathrm{Ge}$ triplejunction industry standard. There are multiple technological routes to achieve four-junction cells with the ideal bandgap combination of $1.9 \mathrm{eV}, 1.4 \mathrm{eV}$ $1.05 \mathrm{eV}$ and $0.7 \mathrm{eV}$. This includes metamorphic growth concepts and direct semiconductor wafer bonded technology. All cell designs have their specific advantages and challenges. Therefore, at Fraunhofer ISE a plurality of different four-junction cell concepts is under investigation. The current status of the development and a discussion of so far achieved characteristics are presented in this work.
\end{abstract}

\section{INTRODUCTION}

Four-junction cells are being developed as the next generation product for space applications to replace today's triple-junction cells where $\mathrm{Ga}_{0.49} \mathrm{In}_{0.51} \mathrm{P}(1.9 \mathrm{eV})$ and $\mathrm{Ga}_{0.99} \mathrm{In}_{0.01} \mathrm{As}(1.4 \mathrm{eV})$ are grown on $\mathrm{Ge}(0.7 \mathrm{eV})[1$ 3]. The triple-junction cells are well developed and e.g. the $3 \mathrm{G} 30$ product provided by AZUR SPACE reaches $29.5 \%$ begin-of-life and $26.5 \%$ conversion efficiency under end-of-life conditions $\left(1 * 10^{15} \mathrm{e}^{-/} \mathrm{cm}^{2} 1 \mathrm{MeV}\right.$ electron irradiation) [4]. Slightly lower end-of-life results are achieved by Spectrolab [5] and SolAero [6]. However, there is a strong pull for more efficient, lighter and more radiation hard cell designs. The route to higher efficiencies clearly demands a higher number of junctions. Calculations of the ideal bandgaps for four-junctions solar cells shows that for the third subcell a bandgap energy of around $1 \mathrm{eV}$ is imperative. From Figure 1 it can be easily seen that, aside from the diluted nitride material, there is no choice for a lattice matched material to GaAs or Ge with the desired $1 \mathrm{eV}$ bandgap. The $\mathrm{Ga}_{0.93} \mathrm{In}_{0.07} \mathrm{~N}_{0.03} \mathrm{As}_{0.97}$ material has been intensively investigated as a lattice matched $1 \mathrm{eV}$ junction [7-9]. However, due to a low material quality for metal-organic vapour phase epitaxy (MOVPE) grown materials [10], such four-junction cells have failed to surpass the triple-junction performance[11]. Thus, new cell concepts have evolved where the lattice matching constraint has been dropped.

They contain either one or more metamorphic buffer layers where the lattice constant is increased, so that GaInAs junctions with different Indium contents are used as sub-cells $[1,3,12]$. For example, the upright metamorphic four-junction solar cell architecture developed by AZUR SPACE (4G32) is introduced to space qualification by the end of 2016 [1]. This cell architecture is an evolutionary development of an upright metamorphic triple-junction cell previously developed at Fraunhofer ISE for terrestrial concentrator applications [13]. Recently a four-junction inverted metamorphic cell has been introduced as a product by SolAero where $32.7 \%$ efficiency is reported at begin-oflive while $26.4 \%$ remain after irradiation with $1 \mathrm{MeV}$ electrons with a fluence of $1 * 10^{15} \mathrm{e} / \mathrm{cm}^{2}$ according to the data sheet [6]. This corresponds to a remaining factor in maximum power of $81 \%$

Another possibility to realise four-junction solar cells is using the direct semiconductor bonding technology. Here a set of sub-cells has been grown on different substrates and thus on different lattice constants and are bonded afterwards [2, 14]. Both approaches, the metamorphic growth concept and the wafer bonding technology can also be combined.

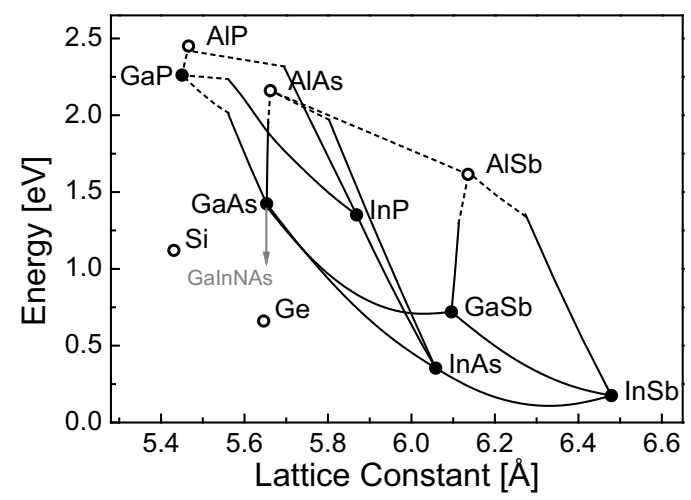

Figure 1. III-V semiconductors: The bandgap is plotted as a function of lattice constant. The filled (open) circles represent (in-)direct semiconductors. The solid (dashed) lines represent the according (in-) direct ternaries.

Figure 2 shows four-junction structures that are being developed at Fraunhofer ISE for the use in space or terrestrial concentrator photovoltaic applications. 


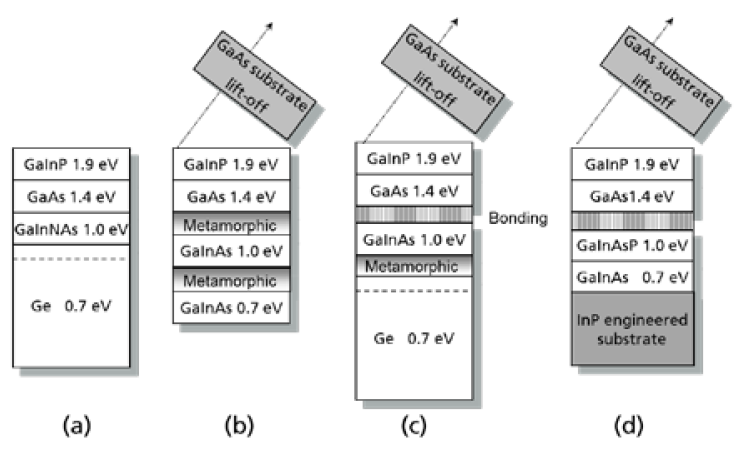

Figure 2. Absorber and substrate materials for fourjunction solar cells: (a) dilute nitride-based, (b) inverted metamorphic, (c) bonded \& metamorphic on Ge and (d) bonded InP based.

The four-junction cell architecture consisting of GaInP/AlGaAs//GaInAsP/GaInAs has been developed by Fraunhofer ISE, SOITEC and CEA-LETI for the use in terrestrial concentrator systems. This solar cell holds the actual record conversion efficiency of $46.0 \%$ at 508 suns under the AM1.5d spectrum $[15,16]$. The cell is built from two separate dual-junction cells grown on GaAs and InP respectively. Each epitaxy process contains only lattice matched materials and therefore achieves high material quality. The two dual-junction solar cells are bonded to form a four-junction solar cell. Here it is noteworthy to mention that an adapted cell design can be also benefical for space applications. Spectrolab has also worked on wafer-bonded cell architectures and reported a 5-junction device with an efficiency of $35.8 \%$ at AM0 conditions [2]. This also proves that more junctions lead to better performances. Fraunhofer ISE and AZUR SPACE are currently developing more radiation hard designs based on the direct wafer bonding approach.

\section{EXPERIMENTAL METHODS}

All epitaxial layers were deposited by metal-organic vapour phase epitaxy with a multi-wafer AIX2800G4TM reactor on 4" Ge, GaAs or InP substrates using standard precursors and process conditions.

The four-junction solar cell made on germanium and containing a metamorphic GaInAs solar cell (see concept Figure 2c) used semiconductor bonding technology. At Fraunhofer ISE we use an Ayumi Industries Co. Ltd bonding chamber (SAB-100) with a fast atom beam surface activated process. Here, an argon beam in a high vacuum environment $\left(<3 * 10^{-6} \mathrm{~Pa}\right)$ is used to clean and deoxidize the surfaces of both wafers just before bringing the surfaces in contact.

Photolithography, wet chemical etching and evaporation of anti-reflection coatings and metal contacts are used to finalize the solar cells.

The transfer matrix method [17] has been used to identify the best bandgaps and absorber thicknesses for an optimized begin-of-life performance. Here, the absorption and transmission of every single layer within the solar cell is calculated. Moreover, assuming that every absorbed photon in the active cell layers creates an electron-hole pair (i.e. an internal quantum efficiency of unity), the sub-cell short circuit current density $\left(\mathrm{J}_{\mathrm{sc}}\right)$ for every junction is calculated for the AM0 spectrum. This calculated value is used as a benchmark value during our development. In order to provide a benchmark for the $V_{O C}$ of each four-junction device, dark currents as function of the bandgap and material were analysed. Eventually the dark currents were empirically fitted from the best single-junction data available in literature and Fraunhofer ISE. For such idealized cells, a fill factor $>88 \%$ is calculated. However, as a one diode model with an ideality-factor of 1 was used for modelling the sub-cells and distributed resistance effects are neglected, this fill factor depicts an upper limit. In a realistic device we expect to achieve fill factors close to $86 \%$

\section{TECHNOLOGICAL BUILDING BLOCKS}

\subsection{Metamorphic Growth}

Metamorphic buffers are used to change the lattice constant during the growth which will inevitably introduce crystal defects. The requirements of such a metamorphic buffer include the following: change the in-plane lattice constant to the desired target (pseudo substrate) while keeping a low surface roughness, contain the defects in the buffer to allow for high quality material to be grown above the buffer, and lastly be transparent to the transmitted light. For increasing the lattice constant starting from Germanium or GaAs (see Figure 1) this is typically realized by growing a number of layers with an increased Indium composition for every layer. (step-graded buffers). During the continuous growth, the critical thickness is passed and the layers will relax by forming misfit segments which change the in-plane lattice constant.

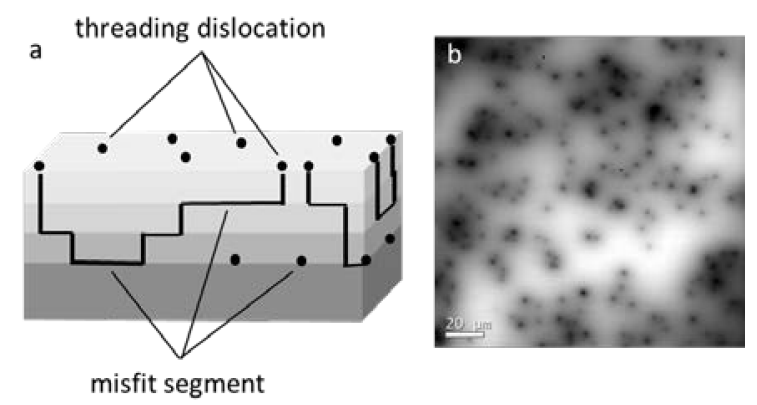

Figure 3. a) Schematic of a step-graded buffer showing misfit segments and threading dislocations. $b$ )

Cathodoluminescence image of a GaInAs double heterostructure above a step-graded buffer on GaAs with a target Indium composition of $20 \%$. The threading dislocation density is below $1 * 10^{6} \mathrm{~cm}^{-2}$. 
However, every misfit segment typically begins and ends with a threading dislocation (Figure 3a).

The threading dislocations continue in the subsequent growth, where they form non-radiative recombination centres in the active region of the solar cell. The density of the threading dislocation depends on the buffer design and growth conditions including temperature, misfit grading rate, growth rate, V-III ratio, surfactants, possible wafer miscut orientations, material choice and target lattice constant. Thus a careful engineering of the process is necessary. A cathodoluminescence image can visualize the threading dislocation density (TDD), as the areas of high non-radiative recombination around a threading dislocation appear dark (Figure 3b). For high performance sub-cells, TDDs below $1 * 10^{6} \mathrm{~cm}^{2}$ are typically desired. We achieved such low TDDs in GaInAs buffers up to a misfit of $1.3 \%$ [18].

\subsection{Direct Semiconductor Bonding}

The requirements of a semiconductor bond within a multi-junction cell are low electrical resistance, no optical absorption or reflection and high mechanical stability. This is readily fulfilled for most direct semiconductor bonds as the two semiconductors are in direct contact and form covalent bonds after a short annealing treatment at moderate temperatures. When the doping of the two joined layers is high enough, typical bond resistances lead to a voltage loss of less than $1 \mathrm{mV}$ at current densities below $17 \mathrm{~mA} / \mathrm{cm}^{2}$ (see Figure 4). Bonding allows the combination of a wide range of different materials. Low resistance bonds between various materials have already been demonstrated including $\mathrm{Si} / / \mathrm{GaAs}$, InP//GaAs and $\mathrm{GaSb} / / \mathrm{GaInAs}$ [1921]

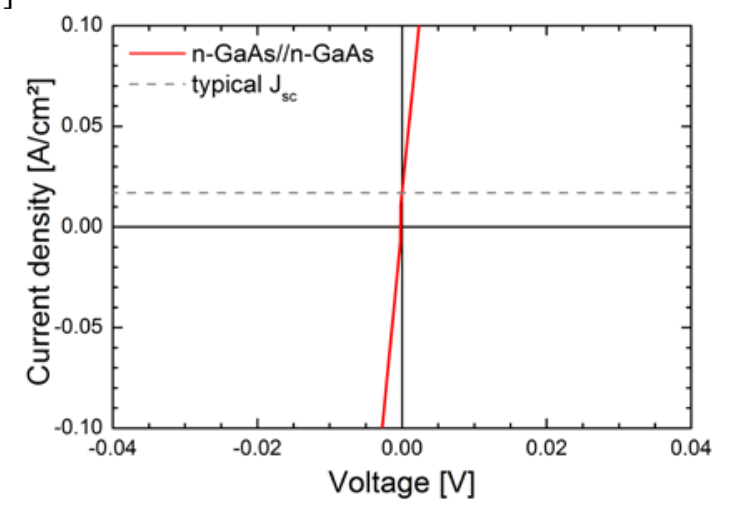

Figure 4.Typical I-V curve of a $n-G a A s / n-G a A s$ direct bond after annealing at $400^{\circ} \mathrm{C}$ for $60 \mathrm{~s}$. The dashed grey line symbolizes the typical short-current density of fourjunction cells at AMO. The voltage loss due to bond resistance at $17 \mathrm{~mA} / \mathrm{cm}^{2}$ is below $1 \mathrm{mV}$.

However a critical condition for direct semiconductor bonding is the surface roughness which typically needs to be below $1 \mathrm{~nm}$ (RMS). Furthermore, all particles present at the surface will cause voids in the bond or even wafer breakage. Thus, the wafers are currently treated after epitaxy before the bonding with a chemical mechanical polishing process to ensure a clean surface and a low surface roughness.

With this process, full 4" wafers have been bonded with no or very few voids (Figure 5) suggesting that this method is viable for large area devices such as space solar cells.

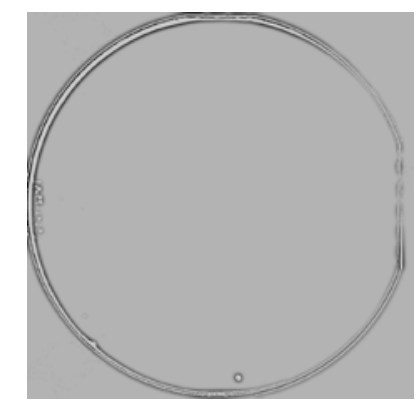

Figure 5. Surface acoustic microscopy image of a 4" InP//GaAs direct bond performed at Fraunhofer ISE. The pair of wafers is fully bonded except one void at the bottom (bright spot) corner most likely caused by a particle.

\section{FOUR-JUNCTION CELLS}

In the following, the actual status of three four-junction designs that have been realized at Fraunhofer ISE will be presented (Figure 2a, b, c). Note that some designs have only been explored for terrestrial applications so far and thus are not optimized, i.e. current matched under the AM0 spectrum. However, all four-junction concepts have calculated realistic efficiency potentials above $36 \%$ when optimized for begin of-life performance. The calculated benchmark efficiencies including $\mathrm{V}_{\mathrm{OC}}$ and $\mathrm{J}_{\mathrm{SC}}$ values for the begin-of-life optimized designs (see Figure 2) are displayed in Table 1).

Table 1: Calculated benchmark efficiencies for the begin-of-life optimized four junction structures

\begin{tabular}{|l|c|c|c|}
\hline & $\mathrm{J}_{\mathrm{sc}}\left[\mathrm{mA} / \mathrm{cm}^{2}\right]$ & $\mathrm{V}_{\mathrm{oc}}[\mathrm{V}]$ & $\eta[\%]$ \\
\hline dilute nitride-based (a) & 16.4 & 3.46 & 36.9 \\
\hline inverted metamorphic (b) & 16.4 & 3.62 & 38.4 \\
\hline bonded \& metamorphic on Ge (c) & 16.4 & 3.46 & 36.9 \\
\hline bonded InP based (d) & 16.4 & 3.56 & 37.9 \\
\hline
\end{tabular}

\subsection{Dilute nitride based four-junction}

Dilute nitride $\mathrm{Ga}_{0.93} \mathrm{In}_{0.07} \mathrm{~N}_{0.03} \mathrm{As}_{0.97}$ seems a perfect choice to progress from the standard $\mathrm{GaInP} / \mathrm{GaAs} / \mathrm{Ge}$ triple-junction to a four-junction cell (Figure $2 a$ ) as the material can reach a bandgap of $1 \mathrm{eV}$ while being lattice matched to Ge. However, up to now minority carrier lifetimes in MOVPE grown material are well below 1 ns which is not sufficient to achieve high performances. It should be noted though, that MBE growth has already led to excellent dilute nitride devices [22] which shows that these current problems challenges may be overcome in the future. However, for MOVPE-grown 
materials so far background doping levels above $5^{*} 10^{16} \mathrm{~cm}^{-3}$ have been found due to a strong carbon incorporation. This is one reason why only diffusion lengths in the order of $100 \mathrm{~nm}$ are measured. As a consequence, internal quantum efficiencies below $60 \%$ and $\mathrm{V}_{\mathrm{OC}}$ values below $500 \mathrm{mV}$ for $1 \mathrm{eV}$ materials are typical today. When incorporating such a sub-cell into the triple-junction, the four-junction $\mathrm{J}_{\mathrm{SC}}$ is currently significantly reduced [11] (Figure 6). This resulted in a low efficiency of only $13 \%$ for this device.
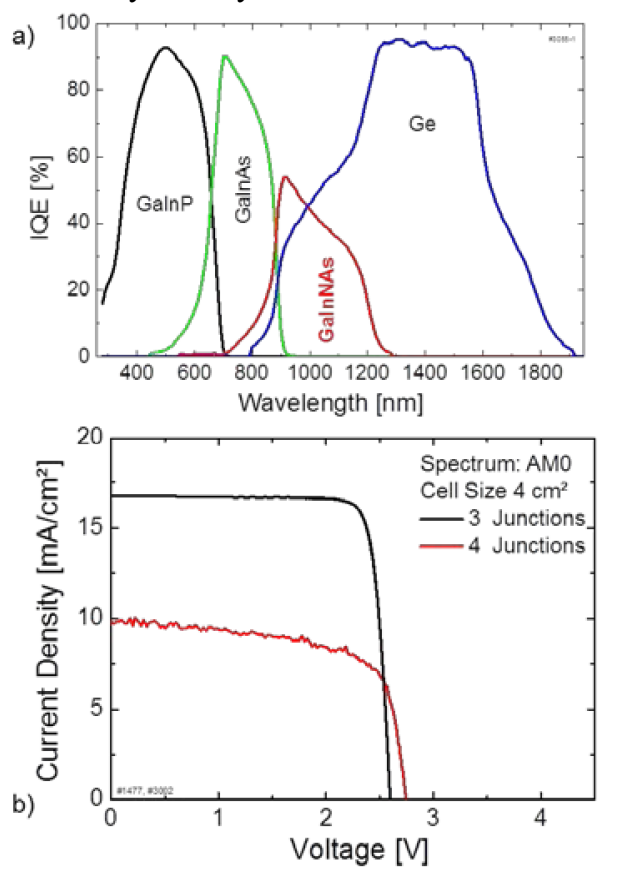

Figure 6. Internal quantum efficiency (IQE)(a) and I-V characteristics (b) of a GaInP/GaAs/GaInNAs/Ge fourjunction cell under AMO. The cell current is clearly limited by the low performance of the GaInNAs junction. The I-V curves under AMO at the bottom shows the comparison between the four-junction (red) and the according triple-junction cell (black). While the $J_{S C}$ is significantly reduced, only a small amount in $V_{O C}$ could be gained (Data taken from [11]).

\subsection{Inverted metamorphic four-junction}

The inverted metamorphic approach also requires only one growth process on one wafer. This comes at the cost of two metamorphic buffers which need to be graded from the lattice constant of GaAs to a new larger lattice constant with a misfit of $3.8 \%$ in total. Considering that high quality buffers with a low TDD are typically grown with a grading rate of $0.5-1 \mu \mathrm{m} / \%$ misfit, another 5 to $10 \mu \mathrm{m}$ of extra epitaxial layers are added for the buffer. After the growth, the substrate needs to be removed and the epitaxial layers need to be transferred to a support substrate that can be a Si wafer or a metal film. At Fraunhofer ISE, such inverted metamorphic cells structures consisting of GaInP (1.9 $\mathrm{eV})$, GaAs $(1.42 \mathrm{eV}), \mathrm{Ga}_{0.73} \operatorname{In}_{0.27} \mathrm{As}(1.05 \mathrm{eV})$ and
$\mathrm{Ga}_{0.47} \mathrm{In}_{0.53} \mathrm{As}(0.75 \mathrm{eV})$ sub-cells have been realized and have been processed into solar cells by AZUR SPACE. The I-V curve of the best present cell is displayed in Figure 7. Currently it reaches an efficiency of $29.4 \%$ under AM0 conditions. Compared with the simulated benchmark (see Table 1) the biggest improvement potential is in $\mathrm{V}_{\mathrm{OC}}$. This is partly due to the fact that the lowest sub-cell still has a TDD of $6^{*} 10^{6} \mathrm{~cm}^{-2}$ which can be improved further. However, a TDD value below $2 * 10^{6} \mathrm{~cm}^{-2}$ has already been reached in a standalone buffer sample, and thus should result in an improved voltage of the GaInAs sub-cells. Improved devices are currently being prepared.

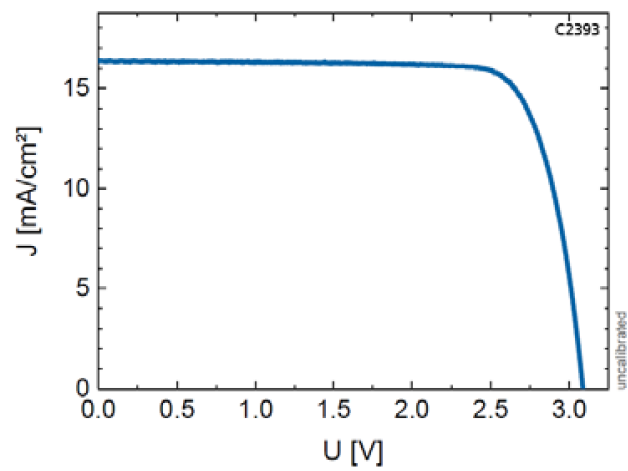

Figure 7. Uncalibrated I-V curve at AM0 for an inverted metamorphic four-junction cell with a $4 \mathrm{~cm}^{2}$ cell area.

The high begin-of-life efficiency potential of this cell design has recently been proven by France et al. who reported an efficiency value of 35.3\% under AM0 [12]. One downside of this approach for space use is, however, that the GaAs and GaInAs junctions show weak radiation hardness compared to GaInP or Ge [23].

\subsection{Bonded and metamorphic on Ge}

The principles of this four-junction cell concept has been developed at Fraunhofer ISE [18]. Currently Fraunhofer ISE and AZUR SPACE continue optimizing the performance for terrestrial usage within the European funded project CPVMatch. This four-junction cell is built from two separate growths: the first is an inverted dual-junction (GaInP $1.9 \mathrm{eV}$ and $\mathrm{Al}_{0.03} \mathrm{Ga}_{0.97} \mathrm{As}$ $1.47 \mathrm{eV}$ ) on GaAs while the second consists of an indiffused Ge cell $(0.66 \mathrm{eV})$ with a metamorphic buffer structure and a $\mathrm{Ga}_{0.81} \mathrm{In}_{0.19} \mathrm{As}$ cell $(1.15 \mathrm{eV})$. Those two wafers are joined by a direct wafer bond and the GaAs substrate is removed before photolithography and metal evaporation. So far this cell has only been optimized for the use in terrestrial concentrator systems and thus the choosen bandgaps and current matching is not ideal for the AM0 spectrum. The metamorphic buffer for this GaInAs cell has been optimized to have a TDD < $1 * 10^{6} \mathrm{~cm}^{-2}$. This allows for the growth of a high quality GaInAs sub-cell. At the bandgap of $1.15 \mathrm{eV}$ a sub-cell $\mathrm{V}_{\mathrm{OC}}$ of $0.754 \mathrm{~V}$ has already been reached. This is of 
comparable material quality to a GaAs junction grown on a GaAs substrate.

The low maximum external quantum efficiency (EQE) in Figure 8 of every sub-cell is caused by the higher grid shading of the concentrator cell design. The calculated sub-cell currents that would be generated under the AM0 spectrum are also shown in the image. A redistribution of the current for perfect current matching would lead to $15.8 \mathrm{~mA} / \mathrm{cm}^{2}$.

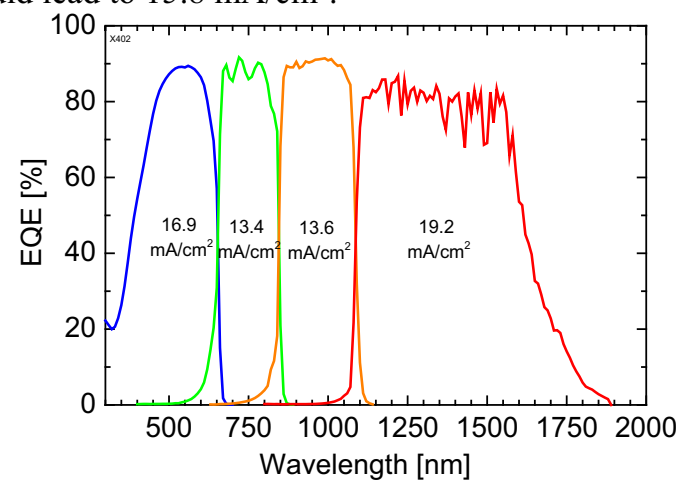

Figure 8. External Quantum Efficiency (EQE) of the metamorphic four-junction cell on Ge. The calculated subcell currents under AMO are included in the figure. Since the cell was optimized for terrestrial applications, a high current mismatch is observed under the AMO spectrum.

The measured $\mathrm{V}_{\mathrm{OC}}$ is $3.32 \mathrm{~V}$ at 1 sun under the $\mathrm{AM} 1.5 \mathrm{~d}$ spectrum. For an ideal bandgap combination for AM0 conditions of $1.9 \mathrm{eV}, 1.42 \mathrm{eV}, 1.05 \mathrm{eV}$ and $0.66 \mathrm{eV}$, the two middle cells would have to be reduced in terms of bandgap. Taking this into account, a $\mathrm{V}_{\mathrm{OC}}$ of $3.17 \mathrm{eV}$ would be expected assuming the same material quality. This is close to the simulated value of $3.46 \mathrm{~V}$ showing the maturity of the cell development and high expected performance of such a design.

\section{CONCLUSION}

To surpass the performance of existing triple-junction space solar cells, four or five-junctions are necessary. At Fraunhofer ISE, different four-junction cell architectures are being developed. All of these structures have been simulated based on realistic material data and the calculated realistic efficiency is above 36\% AM0 when optimized for begin-of-life conditions. For the monolithic direct growth on $\mathrm{Ge}$ the challenge is in integrating a $1 . \mathrm{eV}$ junction. Because the lattice matched material GaInNAs is of too low quality so far, when being deposited by MOVPE. Thus either metamorphic buffer structures and/or wafer bonding have been introduced. The development status of three four-junction cells has been presented: "dilute nitride based", "inverted metamorphic", "metamorphic and bonded on Ge". Still more R\&D is needed to achieve the benchmark efficiencies beyond $36 \%$.

\section{ACKNOWLEDGEMENTS}

The authors like to acknowledge device processing and characterization by M. Scheer, K. Wagner, S. Stättner, R. Freitas, R. Koch, E. Fehrenbacher, A. Wekkeli, S.K. Reichmuth and E. Schäffer. This work was supported the European Space Agency ESA-ESTEC (contract No. 4000112560/14/NL/FE, 4000104852 and RFQ 3$11296 / 07 / \mathrm{NL} / \mathrm{GLC})$, the German Aerospace DLR (contract No. 50RN1301 and 50JR0641) and the European Union (contract No. 283798). M. Niemeyer acknowledges funding of his $\mathrm{PhD}$ work by the German Federal Environmental Foundation (DBU).

\section{REFERENCES}

1. Guter, W., Dunzer, F., Ebel, L., Hillerich, K., Köstler, W., Kubera, T., . . . \& Wächter, C. (2016). Space Solar Cells - 3G30 And Next Generation Radiation Hard Products. in Proc. European Space Power Conference, Thessaloniki, Greece - to be published.

2. Chiu, P.T., Law, D.C., Woo, R.L., Singer, S.B., Bhusari, D., Hong, W.D., . . \& Karam, N.H. (2014) $35.8 \%$ space and $38.8 \%$ terrestrial $5 \mathrm{~J}$ direct bonded cells. 2014 IEEE 40th Photovoltaic Specialists Conference (PVSC). 0011-3.

3. Patel, P., Aiken, D., Boca, A., Cho, A.Y., Chumney, D., Clevenger, M.B., . . \& \& Varghese, T. (2012) Experimental results from performance improvement and radiation hardening of inverted metamorphic multijunction solar cells IEEE Journal of Photovoltaics. 2(3), 377-81.

4. AZUR SPACE Solar Power $\mathrm{GmbH}$, http://www.azurspace.com/index.php/en/products/p roducts-space/space-solar-cells

5. Spectrolab, http://www.spectrolab.com/solarcells.htm

6. SolAero, http://solaerotech.com/products/spacesolar-cells-coverglass-interconnected-cells-cic/

7. Volz, K., Lackner, D., Nemeth, I., Kunert, B., Stolz, W., Baur, C., . . . \& Bett, A.W. (2008) Optimization of annealing conditions of (GaIn)(NAs) for solar cell applications. Journal of Crystal Growth. 310(79), 2222-8.

8. Geisz, J.F. \& Friedman, D.J. (2002) III-N-V semiconductors for solar photovoltaic applications. Semiconductor Science and Technology. 17(8), 769-77.

9. Garrod, T.J., Kirch, J., Dudley, P., Kim, S., Mawst, L.J. \& Kuech, T.F. (2011) Narrow band gap GaInNAsSb material grown by metal organic vapor phase epitaxy (MOVPE) for solar cell applications Journal of Crystal Growth. 315(1), 68-73. 
10. Baur, C., Bett, A.W., Dimroth, F., van Riesen, S., Kunert, B., Traversa, M., . . . \& Stolz, W. (2003). Development of a $1.0 \mathrm{eV}$ (GaIn)(NAs) Solar Cell. in Proc. Technical Digest of the 3rd World Conference on Photovoltaic Energy Conversion, Osaka, Japan. pp.677-680

11. Essig, S., Stämmler, E., Rönsch, S., Oliva, E., Schachtner, M., Siefer, G., . . . \& Dimroth, F. (2011). Dilute nitrides for 4- and 6- junction space solar cells. in Proc. 9th European Space Power Conference, St.-Raphael, France.

12. France, R.M., Geisz, J.F., Garcia, I., Steiner, M.A., McMahon, W.E., Friedman, D.J., . . . \& Olavarria, W.J. (2015) Design Flexibility of Ultrahigh Efficiency Four-Junction Inverted Metamorphic Solar Cells. IEEE Journal of Photovoltaics. PP(99), 1-6.

13. Guter, W., Schöne, J., Philipps, S.P., Steiner, M., Siefer, G., Wekkeli, A., . . . \& Dimroth, F. (2009) Current-matched triple-junction solar cell reaching $41.1 \%$ conversion efficiency under concentrated sunlight. Applied Physics Letters 94(22), 223504-6.

14. Dimroth, F., Tibbits, T.N.D., Beutel, P., Karcher, C., Oliva, E., Siefer, G., . . . \& Hannappel, T. (2014) Development of high efficiency wafer bonded 4-junction solar cells for concentrator photovoltaic applications. 40th IEEE Photovoltaic Specialists Conference. 0006-10

15. Tibbits, T.N.D., Beutel, P., Grave, M., Karcher, C., Oliva, E., Siefer, G., . . . \& Dobrich, A. (2014). New Efficiency Frontiers With Wafer-Bonded Multi-Junction Solar Cells. in Proc. 29th European Photovoltaic Solar Energy Conference, Amsterdam, Netherlands. pp 1975-8

16. Green, M.A., Emery, K., Hishikawa, Y., Warta, W. \& Dunlop, E.D. (2016) Solar cell efficiency tables (version 47). Progress in Photovoltaics: Research and Applications. 24(1), 3-11.

17. Létay, G., Breselge, M. \& Bett, A.W. (2003). Calculating the Generation Function of III-V Solar Cells. in Proc. Proceedings of the 3rd World Conference on Photovoltaic Energy Conversion, Osaka, Japan. pp 741-4

18. Dimroth, F., Tibbits, T.N.D., Niemeyer, M., Predan, F., Beutel, P., Karcher, C., . . \& \& Signamarcheix, T. (2015). Four-junction wafer bonded concentrator solar cells. in Proc. Photovoltaic Specialist Conference (PVSC), 2015 IEEE 42nd, pp 0006-10

19. Essig, S. \& Dimroth, F. (2013) Fast atom beam activated wafer bonds between $\mathrm{n}-\mathrm{Si}$ and $\mathrm{n}-\mathrm{GaAs}$ with low resistance. ECS Journal of Solid State Science and Technology. 2(9), Q178-81.

20. Predan, F., Reinwald, D., Klinger, V. \& Dimroth, F. (2015) Transparent and electrically conductive $\mathrm{GaSb} / \mathrm{Si}$ direct wafer bonding at low temperatures by argon-beam surface activation. Applied Surface Science. 353(1203 - 1207.
21. Tauzin, A., Lagoutte, E., Salvetat, T., Guelfucci, J., Bogumilowicz, Y., Imbert, B., . . . \& Dimroth, F. (2016) InP-based composite substrates for four junction concentrator solar cells. AIP Conference Proceedings. 1679(1), pp 040009.

22. Sabnis, V., Yuen, H. \& Wiemer, M. (2012). Highefficiency multijunction solar cells employing dilute nitrides. in Proc. 8th International Conference on Concentrating Photovoltaic Systems, Toledo, Spain.

23. Yamaguchi, M. (2001) Radiation-resistant solar cells for space use. Solar Energy Materials and Solar Cells. 68(1), 31-53. 